\title{
THE “ARMS RACE” ON AMERICAN ROADS: THE EFFECT OF SPORT UTILITY VEHICLES AND PICKUP TRUCKS ON TRAFFIC SAFETY*
}

\author{
MICHELLE J. WHITE \\ University of California, San Diego
}

\begin{abstract}
Drivers have been running an "arms race" on American roads by buying increasingly large vehicles such as sport utility vehicles and light trucks. But large vehicles pose an increased danger to occupants of smaller vehicles and to pedestrians, bicyclists, and motorcyclists. This paper measures both the internal effect of large vehicles on their own occupants' safety and their external effect on others. The results show that light trucks are extremely deadly. For each 1 million light trucks that replace cars, between 34 and 93 additional car occupants, pedestrians, bicyclists, or motorcyclists are killed per year, and the value of the lives lost is between $\$ 242$ and $\$ 652$ million per year. The safety gain that families obtain for themselves from driving large vehicles comes at a very high cost: for each fatal crash that occupants of large vehicles avoid, at least 4.3 additional fatal crashes involving others occur.
\end{abstract}

\section{INTRODUCTION}

$\mathrm{D}$ cars with sport utility vehicles (SUVs) and pickup trucks and then replacing these vehicles with even larger SUVs and even heavier trucks, including the tank-like Hummer. From 1980 to 2000, the proportion of motor vehicles that are SUVs or light or heavy trucks increased from .22 to $.39 .{ }^{1}$ An important reason for the popularity of large vehicles is that families view them as providing better protection to their occupants if a crash occurs. But because SUVs and light trucks are taller, heavier, and more rigid than cars, they pose an increased danger to occupants of cars and to pedestrians, bicyclists, and

\footnotetext{
* I am grateful to Emily Tang for research assistance and to Eli Berman, Glenn Blomquist, Roger Gordon, Howard Gruenspecht, Valerie Ramey, Matthew Neidell, Steve Carroll, Bob Reville, and the editors for very helpful comments. The Institute of Civil Justice at RAND and the National Science Foundation, under grant 0212444, provided research support. An earlier version of this paper appeared as National Bureau of Economics Working Paper No. 9302.

${ }^{1}$ The figure for 1980 is slightly understated because SUVs were counted as cars in 1980 and as light trucks in 2000. See U.S. Census Bureau, Statistical Abstract of the United States, table 1062 (2002).
}

[Journal of Law and Economics, vol. XLVII (October 2004)]

(C) 2004 by The University of Chicago. All rights reserved. 0022-2186/2004/4702-0011\$01.50 
motorcyclists. Greater height means that when SUVs or light trucks strike cars, they hit car occupants' upper bodies and heads rather than their lower bodies, causing greater injury. And when SUVs and light trucks strike pedestrians, bicyclists, or motorcyclists, victims are hit in the body and crushed. In contrast, when cars strike pedestrians, bicyclists, or motorcyclists, victims are usually hit in the legs and thrown onto the car's hood, which is relatively soft. In addition, while cars are designed with "crumple zones" to absorb the impact of a crash, SUVs and light trucks are much stiffer. They therefore absorb less of the force of the crash and transfer more to cars. ${ }^{2}$

In this paper, I use microlevel data on crashes to measure both the internal effect of light trucks and SUVs on their own occupants' safety when crashes occur and the external effect of light trucks and SUVs on occupants of cars, pedestrians, bicyclists, and motorcyclists. The internal effect is the increase in safety that light trucks and SUVs provide to their own occupants when crashes occur. The negative external effect is the harm that light trucks and SUVs cause to occupants of cars and to pedestrians, bicyclists, and motorcyclists when crashes occur.

The results of the paper show that light trucks are extremely deadly. When drivers shift from cars to light trucks or SUVs, each crash involving fatalities of light-truck or SUV occupants that is prevented comes at a cost of at least 4.3 additional crashes that involve deaths of car occupants, pedestrians, bicyclists, or motorcyclists. The results also suggest that when behavioral changes are taken into account, large vehicles actually endanger their own occupants rather than protect them. The safety benefit of substituting cars for light trucks and SUVs on the road is found to be similar in magnitude to the benefit of seat belts.

Section II of the paper reviews the literature, and Section III provides a simple model of the external effects of light trucks. Sections IV and V describe the data and the results. Section VI examines the effect of a policy change in which 1 million cars replace light trucks and SUVs. Section VII examines why liability rules and other legal institutions fail to internalize the negative external effects of heavy vehicles. Section VIII is the conclusion.

\section{BACKGROUND}

The effect of vehicle size on traffic safety has long been controversial, with some researchers arguing that larger vehicles increase traffic safety and

\footnotetext{
${ }^{2}$ See Leonard Evans, Car Size and Safety: Results from Analyzing U.S. Accident Data (Working paper, Gen. Motors Res. Laboratories 1985); National Highway Traffic Safety Administration, A Collection of Recent Analyses of Vehicle Weight and Safety (Working Paper No. HS-807 677, U.S. Dep’t Trans., May 1991); National Highway Traffic Safety Administration, The Effect of Decrease in Vehicle Weight on Injury Crash Weights (Working Paper No. HS-808 575, U.S. Dep't Trans., January 1997); and Keith Bradsher, High and Mighty: SUVs-The World's Most Dangerous Vehicles and How They Got That Way, ch. 9 (2002), for discussion.
} 
others arguing the opposite. The controversy dates from the 1970s, when federal-government-mandated increases in fuel economy standards (CAFE standards) led automakers to reduce vehicle weight. Robert Crandall and John Graham used aggregate U.S. data for the 1970s and 1980s to argue that adoption of the CAFE standards and the resulting reduction in vehicle weight caused many additional traffic deaths and serious injuries. ${ }^{3}$ More recently, Douglas Coate and James VanderHoff used state-level data for several years in the 1990s to argue that the increase in the proportion of U.S. vehicles that consists of SUVs and light trucks has reduced traffic fatalities. ${ }^{4}$

Other researchers have argued that larger vehicles reduce safety on the basis of either crash data or tests in which two vehicles are crashed into each other. John Meyer and Jose Gomez-Ibanez ${ }^{5}$ discuss evidence from a New York State study that found that when a small car is involved in a crash with another car that is large rather than small, occupants of the small car are 42 percent more likely to be seriously injured. Conversely, when a large car is involved in a crash with another car that is small rather than large, occupants of the large car are 29 percent less likely to be seriously injured. ${ }^{6}$

These contradictory views suggest that the overall impact of vehicle weight and/or size on traffic safety is a mixture of two effects. First, if larger vehicles protect their occupants better in crashes, then an increase in the size of all vehicles would increase traffic safety. However, vehicle fleets are never homogeneous, particularly if pedestrians, bicyclists, and motorcyclists are considered to be "ultralight" vehicles. This means that when some vehicles increase in size, traffic safety may decrease because an increasing proportion of crashes involves vehicles that have different sizes.

To illustrate, suppose there are two types of vehicles in a fleet-small and large. Ten crashes per year occur, and all crashes involve randomly chosen

\footnotetext{
${ }^{3}$ Robert W. Crandall \& John D. Graham, The Effect of Fuel Economy Standards on Automobile Safety, 32 J. Law \& Econ. 97 (1989).

${ }^{4}$ See Douglas Coate \& James VanderHoff, The Truth about Light Trucks, Regulation, Spring 2001, at 22. Because the Crandall-Graham and Coate-VanderHoff studies both use aggregate data over multiple-year periods, they encounter the difficulty that changes in mandated safety equipment and practices, such as seat belts, antilock brakes, air bags, strengthened door panels, and laws requiring use of seat belts, occurred over the same period. As a result, the Coate and VanderHoff study may attribute the reduction in fatalities to the rise in the number of SUVs and light trucks when it is actually due to safety improvements. Using microdata on crashes rather than aggregate data makes it possible to separate out these effects. See also Theodore E. Keeler, Highway Safety, Economic Behavior, and Driving Enforcement, 40 Am. Econ. Rev. 684 (1994).

${ }^{5}$ John R. Meyer \& Jose A. Gomez-Ibanez, Autos, Transit and Cities 264 (1981).

${ }^{6}$ See also Insurance Institute for Highway Safety, Crash Compatibility: How Vehicle Type, Weight Affect Outcomes (1998); Hand Joksch, Dawn Massie, \& Robert Pickier, Vehicle Aggressivity: Fleet Characterization Using Traffic Collision Data (Working Paper No. HS-808 679, U.S. Dep't Trans. 1998); Tom Wenzel \& Marc Ross, Are SUVs Really Safer Than Cars? (Working paper, Envtl. Energies Tech. Div., Lawrence Berkeley Nat'l Laboratory, Fall 2002); and Ted Gayer, Motor Vehicle Regulations and the Fatality Risks of Sport-Utility Vehicles, Vans and Pickups (Working paper, Georgetown Univ. 2002).
} 
pairs of vehicles. Crashes may therefore involve two small vehicles, two large vehicles, or one small and one large. Suppose the cost per crash involving a small and a large vehicle is $\$ 50$, the cost per crash involving two small vehicles is $\$ 45$, and the cost per crash involving two large vehicles is $\$ 40$. Initially, the fleet consists of all small vehicles, so total crash costs are $\$ 450$ per year. But if 10 percent of small vehicles are replaced by large vehicles, the cost of crashes rises to $\$ 458.50$, because some crashes of two small vehicles are replaced by costlier crashes of one small and one large vehicle. The total cost of crashes is maximized when the fleet consists of 60 percent small and 40 percent large vehicles; then the total cost is $\$ 466$. If the fleet shifts entirely to large vehicles, then the total cost of crashes falls to $\$ 400$, since all crashes involve two large vehicles.

This suggests that the effect on safety of an increase in average vehicle size could either be positive or negative, depending on fleet composition and the relative costs of different types of crashes. Thus, when small cars were substituted for large in response to government-mandated CAFE standards, crash costs may have risen because more crashes involved a small and large car rather than two large cars. Similarly, the substitution of SUVs and pickup trucks for cars in recent years may have increased crash costs because more crashes now involve a car and an SUV or pickup, rather than two cars. I discuss these issues further below. ${ }^{7}$

There is also a literature by both economists and engineers on the behavioral response to changes in vehicle characteristics. Sam Peltzman argued that drivers respond to the increased safety that seat belts provide by driving faster. ${ }^{8}$ Leonard Evans argued that drivers drive more safely in small cars than in large cars, presumably to compensate for the greater danger they face. ${ }^{9}$

\section{THEORY}

Suppose a particular driver's vehicle has a two-vehicle crash with a randomly selected other vehicle, including pedestrians, bicyclists, or motorcyclists as ultralight vehicles. Drivers are assumed to choose the size of their vehicles. Suppose a particular driver drives a vehicle of size $s$ and other drivers on average drive vehicles of size $S$. There are $N$ other drivers. The probability of the particular driver having a two-vehicle crash with any other driver is denoted $p(s, S)$, which depends on the size of both the particular driver's vehicle and other drivers' vehicles. Greater size is assumed to increase the probability of crashes, so $p_{s}, p_{s}>0$. In a crash, occupants of the

\footnotetext{
${ }^{7}$ In the analysis below, I also consider whether large vehicles are more likely to have singlevehicle crashes than small vehicles and whether driving behavior differs systematically by vehicle size.

${ }^{8}$ Sam Peltzman, The Effects of Automobile Safety Regulation, 83 J. Pol. Econ. 677 (1975).

${ }^{9}$ Leonard Evans, Accident Involvement Rate and Car Size (Working paper, Gen. Motors Res. Laboratories 1983); and Evans, supra note 2.
} 
particular driver's vehicle suffer damage of $d(s, S)$, and occupants of the other driver's vehicle suffer damage of $D(s, S)$. When either vehicle is larger, its own damage in a two-vehicle crash is smaller, but damage to the other vehicle is larger, so $d_{s}, D_{s}<0$ but $d_{s}, D_{s}>0$.

In addition to two-vehicle crashes, single-vehicle crashes may occur in which vehicles go off the road or hit a fixed object such as a tree or a highway barrier. Suppose the particular driver's probability of a single-vehicle crash is denoted $\rho(s)$. Damage to the vehicle's occupants in this type of crash is denoted $\delta(s)$. The same terms for other drivers are denoted $P(S)$ and $\Delta(S)$. Larger vehicles are assumed to have higher probabilities of single-vehicle crashes and higher damage in these crashes, so $\rho_{s}, \delta_{s}, P_{s}, \Delta_{s}>0$. Finally, assume that vehicle size is measured in units costing $\$ 1$ each. ${ }^{10}$

The social cost of vehicle size is

$$
s+N S+N p(s, S)[d(s, S)+D(s, S)]+\rho(s) \delta(s)+N P(S) \Delta(S) .
$$

The social cost of vehicle size includes the cost of purchasing larger vehicles plus the expected cost of two-vehicle and single-vehicle crashes. Note that drivers' utility gain from driving larger, taller, and/or more threatening vehicles-which the auto industry refers to as drivers' "reptilian" instinct-is ignored. ${ }^{11}$ Also, to keep the model simple, the number of miles driven is treated as fixed.

The first-order conditions defining optimal vehicle size for the particular driver and other drivers are

$$
1+N\left(p D_{s}+p_{s} D\right)+\left(\rho_{s} \delta+\rho \delta_{s}\right)+N\left(p d_{s}+p_{s} d\right)=0
$$

and

$$
1+\left(p d_{S}+p_{S} d\right)+\left(P \Delta_{S}+P_{S} \Delta\right)+\left(p D_{S}+p_{S} D\right)=0 .
$$

In equation (2), $N\left(p D_{s}+p_{s} D\right)$ is the marginal harm to other drivers involved in two-vehicle crashes when the particular driver drives a larger vehiclethe external effect. It must be positive since the particular driver imposes greater damage on other vehicles' occupants by driving a larger vehicle. The next set of terms, $\left(\rho_{s} \delta+\rho \delta_{s}\right)+N\left(p d_{s}+p_{s} d\right)$, is the marginal benefit to the particular driver from driving a larger vehicle-the internal effect. Of the four terms in the internal effect, three are positive and only one- $N p d_{s}$-is

\footnotetext{
${ }^{10}$ This model extends the standard law and economics model of the choice of care to consider the choice of vehicle size. See Steven Shavell, Economic Analysis of Accident Law (1987); Michelle J. White, An Empirical Test of the Comparative and Contributory Negligence Rules in Accident Law, 20 RAND J. Econ. 308 (1989); and Aaron S. Edlin, Per-Mile Premiums for Auto Insurance (Working Paper No. 6934, Nat'l Bur. Econ. Res. 1999). See Yu-ping Liao \& Michelle J. White, No-Fault for Motor Vehicles: An Economic Analysis, 4 Am. L. \& Econ. Rev. 258 (2002), for a game-theoretic version of the model that focuses on the strategic interaction between the particular driver's care level and that of other drivers. Note that the number of miles driven is treated as fixed.

${ }^{11}$ See Bradsher, supra note 2, ch. 6, for discussion.
} 
negative. The particular driver incurs higher expected crash damage in singlevehicle crashes and is more likely to be involved in two-vehicle crashes when she drives a larger vehicle, but her damage when she is involved in twovehicle crashes is smaller. Suppose for the moment that the overall sign of the internal effect is negative, so the particular driver's own crash costs fall when she drives a larger vehicle. (This issue is investigated in the empirical work below.)

In order for equation (2) to hold as an equality, the negative internal effect must exceed the positive external effect and the combined value of both effects must decline in absolute value from $>1$ to $<1$ as $s$ rises. Assuming that this condition holds for the particular driver, equation (2) determines an internal solution for the particular driver's optimal vehicle size, $s^{*}$. However, corner solutions are likely to occur. If the internal effect is negative overall and large compared with the external effect at all values of $s$, then the optimal vehicle size is the largest possible vehicle. Alternately, if the internal effect is positive rather than negative overall, then the optimal vehicle size is the smallest possible vehicle. The same types of conditions hold for other drivers' optimal vehicle size.

Now consider the particular driver's private cost of vehicle size. Assume for simplicity that drivers always bear their own crash damage and are never liable for other drivers' crash damage. (The effect of alternate liability rules is considered below.) Then the particular driver's expected private cost of vehicle size is $s+N p d+\rho \delta$. Treating other drivers' choice of vehicle size as fixed, the particular driver chooses her vehicle size to satisfy

$$
1+\left(\rho \delta_{s}+\rho_{s} \delta\right)+N\left(p d_{s}+p_{s} d\right)=0 .
$$

Equation (4) is identical to equation (2), except that the external effect disappears. Therefore, the particular driver chooses her vehicle size to equate the internal effect to the marginal cost of size. Equation (4) holds as an equality if the overall internal effect is negative, and its absolute value declines from $>1$ to $<1$ as $s$ rises. Assuming that equations (2) and (4) both have internal solutions, the particular driver has an incentive to choose an inefficiently large vehicle because she ignores the external costs of her vehicle size to other drivers. Since other drivers face the same distortion, they all drive inefficiently large vehicles. ${ }^{12}$

In reality, drivers choose care levels in driving as well as choosing vehicle size, and the model suggests that these choices are related. Suppose the particular driver shifts to a larger vehicle. As a result, her own expected crash

\footnotetext{
${ }^{12}$ Corner solutions are also likely in this case. If the internal effect is large and negative at all values of $s$, then the particular driver chooses the largest possible vehicle. In this situation there is no negative externality if the optimal vehicle size is also the largest possible vehicle. Alternately, if the internal effect is positive overall or negative but small, there may be no negative externality because both the social and private first-order conditions imply that the best choice is the smallest possible vehicle.
} 
damage may be lower and she may therefore choose a lower care level in driving. ${ }^{13}$ But lower care and larger vehicle size increase the particular driver's external effect on other drivers, since both changes raise other drivers' expected crash damage.

In the empirical work, I use microlevel data on crashes to estimate the internal and external effects of driving larger vehicles.

\section{DATA}

The data set is a sample of police-reported motor vehicle crashes that were produced by the National Highway Traffic Safety Administration General Estimates System. ${ }^{14}$ To my knowledge, economists have not previously analyzed these data. Detailed information is provided concerning vehicle types of all vehicles that were involved in each crash, the circumstances of the crash, and the injuries that were sustained by all persons who were involved in the crash. I divide vehicles into three categories: cars, light trucks (including SUVs, vans, and pickup trucks), and heavy trucks (including large trucks and buses). ${ }^{15}$ Five types of crashes are examined separately: twovehicle crashes that involve at least one car, two-vehicle crashes that involve at least one light truck, single-vehicle crashes, crashes that involve a vehicle hitting a pedestrian or bicyclist, and crashes that involve a vehicle and a motorcycle. ${ }^{16}$ The data cover the period $1995-2001 .{ }^{17}$

\section{Specification and Results}

The basic specification is a logit regression that explains fatalities or serious injuries in particular types of crashes (where serious injuries are defined as disabling or incapacitating). I discuss the results for each type of crash separately.

\footnotetext{
${ }^{13}$ Evans, supra note 2, provides evidence that drivers of larger vehicles are more likely to be involved in crashes, which suggests that they use less care than drivers of smaller vehicles.

${ }^{14}$ National Highway Traffic Safety Administration, General Estimates System (2004) (available at http://www-nrd.nhtsa.dot.gov/departments/nrd_30/ncsa/GES.html).

${ }^{15}$ I follow the government's classification of SUVs, vans, and pickups as light trucks. The heavy-truck category includes "single-unit straight trucks," combination trucks, and medium or heavy motor homes.

${ }^{16}$ Crashes that involve more than two vehicles (about 6.3 percent of all crashes) and hitand-run crashes are omitted, the latter because no information on the driver is available. Crashes that involve farm equipment, snowmobiles, van-based school buses, and horses are also omitted.

${ }^{17}$ Because the data cover crashes that involve low damage levels or "possible injury," I ignore issues of sample selection bias that were of concern to authors using data on fatal crashes only. See Steven D. Levitt \& Jack Porter, Sample Selection in the Estimation of Air Bag and Seat Belt Effectiveness, 83 Rev. Econ. \& Stat. 603 (2001), for discussion.
} 


\section{A. Fatalities and Serious Injuries in Two-Vehicle Crashes Involving Cars}

Define "vehicle 1" (v1) to be the car and "vehicle 2" (v2) to be the other vehicle. If both vehicles are cars, then one car is chosen randomly to be v1. ${ }^{18}$ The dependent variables are a dummy variable that equals one if one or more occupants of v1 were killed in the crash and a dummy variable that equals one if one or more occupants of v1 were seriously injured or killed. There are approximately 192,000 two-vehicle crashes that involved cars in the data set, including 701 with fatalities and 9,800 with serious injuries.

The key explanatory variables are two dummy variables for whether v2 is a light truck or a heavy truck, where the omitted category is another car. The coefficients of these variables measure the change in the probability of fatalities or serious injuries in v1 when v2 is a light or heavy truck rather than another car. Since the hypothesis is that occupants of cars are more likely to be injured or killed in crashes if the other vehicle is larger, both variables are predicted to have positive signs.

I also include a set of control variables that capture the circumstances of the crash. These include dummy variables for whether the crash occurred in rain, snow, or fog (the omitted category is clear weather), in darkness, in a medium or large city (the omitted category is a small town or rural area), on an interstate highway or a divided highway (the omitted category is a two-way street), and on a weekday. I also include separate dummy variables for whether either driver was male, whether either driver was under 21 or over 60 years old, and interaction terms for whether the driver of either vehicle was both male and under 21. Dummy variables are also included for whether either driver was driving more than 10 miles per hour above the speed limit and for whether either or both were driving negligently (this includes driving when drunk or under the influence of drugs). Separate variables for the number of occupants in each vehicle and whether the driver of v1 wore a seat belt are included. For several of the variables, there are also additional dummy variables for missing data. Year dummies are included to account for the increasing prevalence of air bags and other safety features over the period (use of seat belts is controlled for directly). Weights are used to make the sample representative of all crashes. ${ }^{19}$ Summary statistics are shown in the third column of Table 1 .

The results of the logit regressions that explain fatalities and serious injuries for occupants of $v 1$ are shown in the first two columns of Table 1. Both the

\footnotetext{
${ }^{18}$ This is because the General Estimates System tends to report the vehicle in which the most serious harm occurs as $\mathrm{v} 1$.

${ }^{19}$ The data set does not include the state in which the accident occurred, so state dummy variables cannot be used. But the weights are designed to take care of the problem that different states' reporting systems include varying proportions of accidents of particular types. The weights also offset the oversampling of fatal crashes in the data set.
} 
TABLE 1

Results of Logit Regressions Explaining Fatalities and Serious Injuries to Car Occupants in Two-Vehicle Crashes

\begin{tabular}{|c|c|c|c|c|c|c|}
\hline \multirow[b]{2}{*}{$\mathrm{v} 2=$ Light truck } & \multicolumn{2}{|c|}{ Fatalities } & \multicolumn{2}{|c|}{ Serious Injuries } & \multicolumn{2}{|c|}{ Summary Statistics } \\
\hline & .486 & $(.131)$ & 228 & $(.0288)$ & .445 & (.497) \\
\hline $\mathrm{v} 2=$ Heavy truck & 1.598 & $(.1450)$ & .668 & $(.0454)$ & .0589 & $(.235)$ \\
\hline Medium city & 1.22 & $(.228)$ & .0702 & $(.0417)$ & .116 & $(.320)$ \\
\hline Large city & .847 & $(.130)$ & .381 & $(.0314)$ & .350 & $(.477)$ \\
\hline Seat belt (v1) & -2.56 & (.117) & -1.56 & $(.0382)$ & .825 & $(.380)$ \\
\hline Rain & .070 & $(.160)$ & -.102 & $(.0433)$ & .121 & $(.326)$ \\
\hline Snow & -.489 & $(.320)$ & -.293 & $(.106)$ & .0273 & $(.163)$ \\
\hline Fog & 1.39 & $(.416)$ & .424 & $(.176)$ & .0038 & $(.0617)$ \\
\hline Dark & .561 & $(.114)$ & .316 & $(.0317)$ & .193 & $(.395)$ \\
\hline Weekday & -.174 & (.127) & -.157 & $(.0318)$ & .784 & $(.411)$ \\
\hline Negligent (v1) & -2.23 & (.198) & -.223 & $(.0346)$ & .283 & $(.451)$ \\
\hline Negligent (v2) & -1.23 & $(.175)$ & .0538 & $(.0331)$ & .278 & $(.448)$ \\
\hline Negligent ( $\mathrm{v} 1$ and $\mathrm{v} 2$ ) & 1.24 & (.697) & .379 & $(.0724)$ & .0352 & (.184) \\
\hline Age $<21(\mathrm{v} 1)$ & -.054 & $(.206)$ & -.0992 & $(.0477)$ & .183 & (.387) \\
\hline Age < 21 (v2) & -.083 & $(.334)$ & .0913 & $(.0611)$ & .150 & $(.357)$ \\
\hline Age $>60(v 1)$ & 1.05 & $(.122)$ & .334 & $(.0381)$ & .121 & $(.326)$ \\
\hline Age > 60 (v2) & -.548 & $(.208)$ & .176 & $(.0428)$ & .0990 & $(.299)$ \\
\hline Divided highway & .0551 & (.123) & .251 & $(.030)$ & .239 & $(.426)$ \\
\hline Interstate highway & .123 & $(.178)$ & -.375 & $(.0559)$ & .0480 & $(.214)$ \\
\hline Male driver (v1) & .0841 & $(.115)$ & -.209 & $(.0291)$ & .507 & $(.500)$ \\
\hline Male driver (v2) & .270 & $(.134)$ & .125 & (.0319) & .633 & $(.482)$ \\
\hline Young male (v1) & -.0584 & $(.275)$ & -.157 & $(.0705)$ & .0948 & $(.293)$ \\
\hline Young male (v2) & -.234 & (.403) & -.133 & $(.0767)$ & .0919 & (.289) \\
\hline \multicolumn{7}{|l|}{ Speed $>10 \mathrm{mph}$} \\
\hline \multicolumn{7}{|l|}{ Speed $>10 \mathrm{mph}$} \\
\hline above limit (v2) & 1.17 & $(.475)$ & 1.09 & $(.154)$ & .0021 & $(.0462)$ \\
\hline Occupants (v1) & .318 & $(.0447)$ & .252 & $(.0127)$ & 1.45 & $(.834)$ \\
\hline Occupants (v2) & .0299 & $(.0258)$ & .00945 & $(.0108)$ & 1.44 & $(.960)$ \\
\hline Intercept & -5.10 & $(.309)$ & -2.34 & $(.0737)$ & & \\
\hline Pseudo- $R^{2}$ & .1817 & & .0822 & & & \\
\hline $\begin{array}{l}\text { Mean value of } \\
\text { dependent variable }\end{array}$ & .00152 & $(.0390)$ & .0252 & $(.157)$ & & \\
\hline
\end{tabular}

Note. - The data set consists of all two-vehicle crashes that involve at least one car. Standard errors are in parentheses. For both regressions, year dummies are included and $N=188,423$.

light-truck and heavy-truck dummies have the predicted positive signs and are strongly statistically significant in both models. Among the other variables, occupants of v1 are more likely to be killed or seriously injured in crashes that occur at night or on weekends, in cities rather than rural areas, when either vehicle's speed was more than 10 miles per hour above the limit, when the driver of v1 was more than 60 years old or the driver of v2 was male, and when v1 contained more occupants. Occupants of v1 are less likely to be killed or seriously injured if the driver of v1 wore a seat belt. But, surprisingly, the dummies for male driver and for young male driver generally have negative rather than positive signs, and the signs of the dummy variables for driving negligently are generally negative. 
TABLE 2

Predicted Probabilities of Fatalities and Serious Injuries in CRashes of Different Types

\begin{tabular}{llc}
\hline \hline & $\begin{array}{c}\text { Probability of } \\
\text { Fatalities in v1 }\end{array}$ & $\begin{array}{c}\text { Probability of } \\
\text { Serious Injuries in v1 }\end{array}$ \\
\hline $\begin{array}{l}\text { Two-vehicle crashes involving a car } \\
\text { (v1 = car): }\end{array}$ & .0228 \\
v2 = Car & .000997 & .0282 \\
v2 = Light truck & .00161 & .0254 \\
v2 = Actual distribution of vehicles & .00152 & \\
Two-vehicle crashes involving a light & & .0154 \\
truck (v1 = light truck): & .000645 & .0198 \\
v2 = Car & .00142 & .0163 \\
v2 = Light truck & .000992 & \\
v2 = Actual distribution of vehicles & & .205 \\
Crashes involving a pedestrian or & & .230 \\
bicyclist and a vehicle (v1 = & & \\
pedestrian or bicyclist): & .0181 & \\
v2 = Car & .0329 & .234 \\
v2 = Light truck & & .316 \\
Crashes involving a motorcyclist and a & & \\
vehicle (v1 = motorcycle): & .0241 & .0604 \\
v2 = Car & .0543 & .0637 \\
v2 = Light truck & & \\
Single-vehicle crashes: & .00710 & \\
v1 = Car & & \\
v1 = Light truck & &
\end{tabular}

NotE. - The predicted values are calculated by evaluating the relevant logit regression to obtain the predicted probability of fatalities separately for each observation, using the actual values of the explanatory variables. For the predicted probability of fatalities labeled as "v2 = Light truck," I take a weighted average over all observations in which v2 is a light truck. For the predicted probability labeled as "v2 = Car," I take a weighted average over the light-truck observations but change the value of v2 to be a car. For the predicted probability of fatalities labeled as "v2 = Actual distribution of vehicles," I take a weighted average over all observations.

To get a sense of the importance of the v2 variables, the first two rows of Table 2 show the predicted probabilities of fatalities and serious injuries conditional on a crash. ${ }^{20}$ When a car is involved in a two-vehicle crash with a light truck, the predicted probability of the car occupants suffering one or more fatalities is .00161, compared with .000997 when the other vehicle is another car. Thus, the probability of fatalities for car occupants falls by 38

\footnotetext{
${ }^{20}$ The predicted values are calculated by evaluating the relevant logit regression to obtain the predicted probability of fatalities separately for each observation, using the actual values of the explanatory variables. For the predicted probability of fatalities labeled as "v2 = Light truck" in Table 2, I take a weighted average over all observations in which v2 is a light truck. For the predicted probability of fatalities labeled as "v2 = Car" in Table 2, I take a weighted average over the same set of observations but change the value of v2 to be a car. This assumes that when light-truck drivers shift to driving cars, their demographic characteristics and driving behavior variables remain the same. All other figures in Table 2 are calculated using the same procedure, except those labeled "actual distribution of vehicles," which are discussed below.
} 
TABLE 3

Results of Logit Regressions Explaining Fatalities and Serious InJuries (Coefficients of Vehicle Type Variables Only)

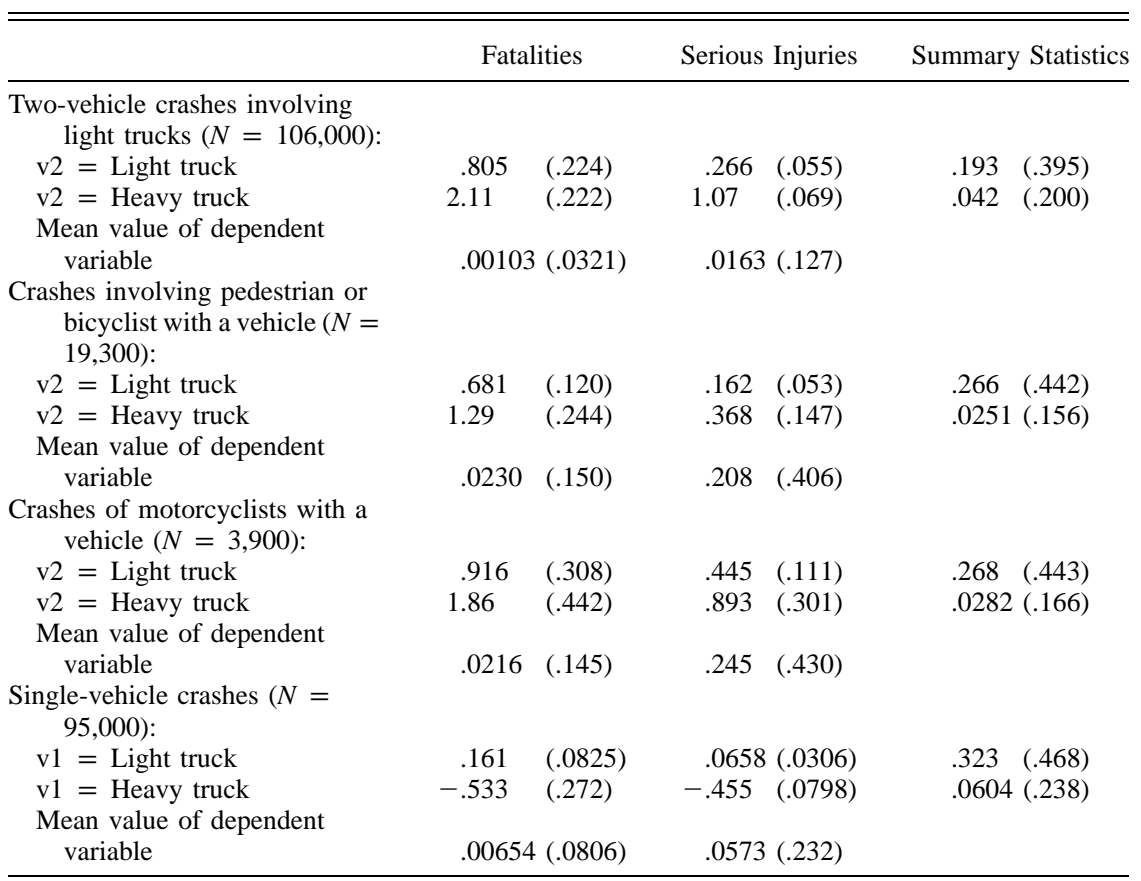

NoTE. - Results are taken from logit regressions explaining fatal and serious-injury crashes in the lighttruck/two-vehicle crash data set, single-vehicle crash data set, pedestrian/bicyclist crash data set, and motorcycle crash data set. Only the coefficients of the light-truck and heavy-truck variables are shown. Figures for number of observations are unweighted.

percent when the other vehicle is a car rather than a light truck. For serious injuries, the reduction is from .0282 to .0228 , or 19 percent.

\section{B. Injuries and Fatalities in Two-Vehicle Crashes Involving Light Trucks}

In this data set, $\mathrm{v} 1$ is the light truck and v 2 is the other vehicle. If both vehicles involved in the crash are light trucks, then one is randomly chosen to be v1. The key explanatory variables again are dummies for whether v2 is a light truck or a heavy truck rather than a car. The predicted signs of the v2 dummies are again positive, since occupants of light trucks are more likely to be killed or injured in two-vehicle crashes if the other vehicle is larger. The control variables are the same as in the previous regressions.

The results of the logit regressions are shown in Table 3. Since the results for the control variables are similar to those for the previous data set, only the coefficients and standard errors of the v2 dummy variables are given. 
(Summary statistics are given in the third column Table 3.) Both v2 variables have positive signs and are strongly statistically significant in both regressions.

Table 2 indicates that if a light truck is involved in a crash with a car rather than another light truck, the probability of fatalities among the lighttruck occupants falls from .00142 to .000645 , or by 55 percent, and the probability of serious injuries among the light-truck occupants falls from .0198 to .0154 , or by 22 percent.

\section{Injuries and Fatalities in Crashes Involving Pedestrians, Bicyclists, and Motorcyclists}

The third and fourth data sets consist of crashes involving a vehicle that hits a pedestrian or bicyclist and a vehicle that hits a motorcyclist, respectively. ${ }^{21}$ In both data sets, the pedestrian, bicyclist, or motorcyclist is $v 1$ and the car or truck is v2. The key explanatory variables again are dummies for whether v2 is a light truck or a heavy truck rather than a car. The hypothesis is that pedestrians/bicyclists and motorcyclists are more likely to be killed or seriously injured when they are struck by light or heavy trucks rather than cars, so the $\mathrm{v} 2=$ light-truck and $\mathrm{v} 2=$ heavy-truck variables are predicted to have positive signs. The control variables are the same as in the previous regressions.

Both v2 dummy variables are positive as predicted and strongly statistically significant in all of the regressions (see Table 3). If a light truck rather than a car hits a pedestrian or bicyclist, the probability of fatalities rises from .0181 to .0329 , or by 82 percent, and the probability of serious injuries rises from .205 to .230 , or by 12 percent. Motorcyclists' probability of being killed rises from .0241 to .0543 , or by 125 percent, in the same circumstances, and their probability of being seriously injured rises from .234 to .316 , or by 35 percent (see Table 2). ${ }^{22}$

\section{Injuries and Fatalities in Single-Vehicle Crashes}

In the last data set, the dependent variables are dummy variables that equal one if one or more occupants of the vehicle involved in the crash were killed or seriously injured. The key explanatory variables are dummies for whether v1 is a light truck or a heavy truck rather than a car. The hypothesis is that because larger vehicles are higher and less stable than cars, they are more likely to kill or seriously injure their occupants in single-vehicle crashes. The

\footnotetext{
${ }^{21}$ Skateboarders, skaters, and people in wheelchairs and baby carriages are included in the pedestrian/bicyclist data set.

${ }^{22}$ A dummy variable is included in the motorcycle crash regressions for whether motorcyclists wore helmets. Surprisingly, it is not statistically significant in either regression.
} 
control variables are similar to those in the previous regressions, but there are no variables for v2.

The coefficients of the light-truck and heavy-truck dummies from the logit regressions are given in Table 3 . The $v 1=$ light truck coefficients are positive and statistically significant in both regressions, but—surprisingly-the $\mathrm{v} 1=$ heavy truck coefficients are negative and statistically significant in both. Thus, people involved in single-vehicle crashes are more likely to be killed or seriously injured if they are driving a light truck rather than a car but less likely to be killed or seriously injured when they are driving a heavy truck rather than a car. ${ }^{23}$ Table 2 indicates that if a light truck rather than a car is involved in a single-vehicle crash, the probability of fatalities rises from .00710 to .00824 , or by 16 percent, and the probability of serious injuries rises from .0604 to .0637 , or by 5 percent.

\section{External versus Internal Effects of Large Vehicles}

Now consider a policy change that causes 1 million light trucks to be replaced by cars. The policy could be a special tax on gas guzzlers, a tax on purchase or registration of SUVs and pickups, or any of a variety of other measures (see the discussion below). I focus on replacing light rather than heavy trucks with cars since most SUVs and pickup trucks are used for nonbusiness purposes and therefore could be replaced by cars without loss of economic efficiency. Because the average numbers of cars and light trucks on U.S. roads during the period of the data set were 132 million and 53 million, respectively, this change is marginal in the sense that it involves expanding the stock of cars by less than 1 percent and reducing the stock of light trucks by less than 2 percent. ${ }^{24}$

I do the calculations in two ways. First, I assume that when light-truck drivers shift to cars, their driving behavior remains the same and so their probability of being involved in crashes remains that of light-truck drivers. This is realistic if drivers tend to sort across vehicle types depending on their driving behavior; that is, reckless drivers choose light trucks and careful drivers choose cars. Second, I assume that when light-truck drivers shift to cars, their driving behavior changes to that of car drivers and their probability of being involved in crashes becomes that of car drivers. This is realistic if driving behavior depends mainly on the type of vehicle driven. (One factor that supports the behavior change assumption is that because drivers of light trucks sit higher relative to the ground than do drivers of cars, they perceive a given speed to be slower and therefore they drive faster-regardless of

\footnotetext{
${ }^{23}$ This result may reflect the fact that drivers of heavy trucks are professionally trained.

${ }^{24}$ The car stock figure is the average number of registered cars in the United States over the sample period. The light-truck figure is computed by adding up all U.S. sales of light trucks between 1990 and the relevant year and then averaging over the sample years. Data are taken from U.S. Census Bureau, supra note 1, tables 1010 and 1062.
} 
TABLE 4

Probability of Crashes per Year by Type of Vehicle and Type of Crash, 1995-2001

\begin{tabular}{llcc}
\hline \hline & \multicolumn{1}{c}{ Cars } & Light Trucks & Percent Difference \\
\hline Two-vehicle crashes & .0274 & .0398 & 45 \\
Single-vehicle crashes & .00788 & .0103 & 31 \\
Vehicle hitting pedestrian or bicyclist & .000741 & .000698 & -6 \\
Vehicle hitting motorcycle & .000174 & .000170 & -2 \\
\hline
\end{tabular}

NOTE. - These figures are the average number of crashes per year by the particular type of vehicle during 1995-2001 divided by the total stock of vehicles of that type. Figures on number of crashes are taken from the National Highway Traffic Safety Administration, General Estimates System (2004), data set. The source for the stock of vehicles is discussed in the text.

their individual driving habits. $)^{25}$ The two assumptions-referred to as "no behavior change" and "behavior change"-are treated as lower- and upperbound estimates of the effect of the policy change.

Table 4 shows the annual probability of crashes by type of crash and type of vehicle during the period of our data. Relative to cars, light trucks are much more likely to be involved in two-vehicle and single-vehicle crashes but are equally as likely as cars to be involved in crashes that involve pedestrians/bicycles and motorcycles.

Table 5 shows the results of the policy change for fatal crashes. Each external and internal effect is shown on a separate row, and the results under the no-behavior-change and behavior-change assumptions are shown in separate columns.

Examine the no-behavior-change assumption first. The first external effect is the reduction in the number of two-vehicle crashes that involve fatalities of car occupants after the policy change. From Table 2, the reduction in the probability of car occupants being killed in two-vehicle crashes when v2 is a car rather than a light truck is $.00161-.000997=.000613$. From Table 4 , the probability of a light truck being involved in a two-vehicle crash is .0398 per year, and this figure is assumed to remain the same after the policy change. Multiplying these figures together and multiplying the result by 1 million, we find that 24 fewer fatal crashes would occur if the policy change were adopted. ${ }^{26}$ The next two external effects are the impacts of the policy change on crashes involving vehicles that hit pedestrians/bicyclists

\footnotetext{
${ }^{25}$ At an extreme, passengers in an airplane flying at high altitude perceive their speed to be close to zero. See Curtis Rist, Roll Over, Newton: The Design of Sport Utility Vehicles Is Enough to Make the Father of Physics Turn in His Grave, Discover, April 2001, at 44.

${ }^{26}$ The first external effect corresponds to the term $p d_{s}$ in equation (4) above. The damage measure $d$ is the probability of fatalities conditional on a crash occurring, so $d_{s}$ is the change in the probability of fatalities when cars have two-vehicle crashes with other cars rather than light trucks; $p$ is the probability of a light truck having a two-vehicle crash. Because the policy change involves 1 million light-truck drivers shifting to cars, $p d_{s}$ is multiplied by 1 million. The other external effects and the first internal effect are computed using the same procedure. All calculations use the sample weights.
} 
TABLE 5

External and Internal EfFects of Replacing 1 Million

Light Trucks with Cars: Fatal Crashes

\begin{tabular}{lcc}
\hline \hline & No Behavior Change & Behavior Change \\
\hline $\begin{array}{l}\text { External effects: } \\
\text { Decrease in number of two-vehicle crashes per year } \\
\quad \text { involving deaths of car occupants }\end{array}$ & -24 & -44 \\
$\begin{array}{l}\text { Decrease in number of crashes per year involving } \\
\text { deaths of pedestrians or bicyclists }\end{array}$ & -10 & -9 \\
$\begin{array}{l}\text { Decrease in number of crashes per year involving } \\
\quad \text { deaths of motorcyclists }\end{array}$ & -5 & -5 \\
$\quad \begin{array}{l}\text { Total external effects } \\
\text { Internal effects: }\end{array}$ & -40 & -58 \\
$\begin{array}{l}\text { Decrease in number of crashes per year involving } \\
\quad \text { deaths of light-truck occupants in single- }\end{array}$ & & \\
$\quad$ vehicle crashes & -12 & -32 \\
$\quad \begin{array}{l}\text { Increase in number of two-vehicle crashes per year } \\
\text { involving deaths of light-truck occupants }\end{array}$ & +21 & +9 \\
$\quad \begin{array}{l}\text { Total internal effects } \\
\text { External plus internal effects }\end{array}$ & +30 & -23 \\
Ratio of external effects to internal effects & 4.3 & -81 \\
Value of the policy change per year (million \$) & 242 & 652 \\
\hline
\end{tabular}

NoTE.-Rounding may affect totals. The calculations with no behavior change assume that when 1 million light-truck drivers shift to cars, the number of crashes of each type in which they are involved per year remains constant. The calculations with behavior change assume that when 1 million light-truck drivers shift to cars, the number of crashes of each type in which they are involved per year changes to the number in which car drivers are involved.

and motorcyclists. Following the same procedure, the policy change reduces the number of fatal crashes involving pedestrians/bicyclists and motorcyclists by 10 and five per year, respectively. Combining all three external effects, the policy change would reduce the number of fatal crashes involving occupants of cars, pedestrians, bicyclists, and motorcyclists by 40 per year.

Now turn to the internal effects of the policy change. Because of the change, 1 million erstwhile light-truck drivers become car drivers and experience car occupants' rather than light-truck occupants' probabilities of being killed or injured in single- or two-vehicle crashes. Consider singlevehicle crashes first. Because light trucks are more dangerous than cars in single-vehicle crashes, the policy reduces the number of single-vehicle crashes that involve fatalities by $(.0103)(.00824-.00710)(1,000,000)$, or by 12 per year. Now consider two-vehicle crashes. I first use the logit regression for the light-truck data set to predict the average probability of fatalities when a light truck is involved in a two-vehicle crash with a randomly selected other vehicle, which is .000992 . (See the figures for actual distribution of vehicles in Table 2.) Then I use the logit regression for the car data set to predict the average probability of fatalities when a car is involved in a twovehicle crash with a randomly selected other vehicle, which is .00152 . The 
difference between these two figures is the increase in the probability of a two-vehicle crash being fatal when drivers shift from driving light trucks to driving cars. If we multiply this difference by the probability of light trucks being involved in two-vehicle crashes and by 1 million, the result is that the policy change increases the number of fatal crashes by 21 per year. Combining the two internal effects, they imply that when 1 million light-truck drivers shift to cars, they and the other occupants of their vehicles experience nine additional crashes involving fatalities per year.

Turning to the overall results, one striking implication is that when drivers choose light trucks rather than cars, the ratio of external to internal effects is $40 / 9=4.3$. This means that for each fatal crash involving occupants of their own vehicles that drivers avoid by choosing light trucks, more than four additional fatal crashes occur involving car occupants, pedestrians, bicyclists, and motorcyclists. In other words, safety gains for those driving light trucks come at an extremely high cost to others.

The right-hand side of Table 5 shows the effects of the policy change under the behavior-change assumption. Specifically, I assume that when drivers shift from light trucks to cars, their crash probabilities change from those of light-truck drivers to those of car drivers. For the first external effect, this means that the change in the number of crashes involving fatalities becomes $[(.000997-.00161)(.0398)+(.0274-.0398)(.00161)](1,000,000)=-44 .{ }^{27}$ This figure is nearly twice as large as the figure of -24 in the no-behaviorchange case. Other figures in the right-hand column of Table 5 are calculated using the analogous procedure.

Both the external and internal effects of the policy change are more favorable in the behavior-change case, that is, more fatal crashes that involve both occupants of the driver's own vehicle and occupants of other vehicles, pedestrians, bicyclists, and motorcyclists are avoided. An important difference between the two sets of results is that the overall internal effect changes sign, from nine additional fatal crashes to 23 fewer fatal crashes. This is because in the behavior-change case, drivers who switch from light trucks to cars become safer, since the reduction in the number of single-vehicle crashes more than offsets the extra danger of being involved in a two-vehicle crash with a larger vehicle. This result implies that driving a light truck rather than a car provides no safety gain for the light-truck occupants-they would be safer driving cars. Overall, the number of fatal crashes avoided as a result of the policy change nearly triples in the behavior-change case, from 30 to 81 per year. Because both the internal and the external effects of the policy

${ }^{27}$ The first external effect in the behavior-change case corresponds to $p d_{s}+p_{s} d$ in equation (4) above. The first term is the same as in the no-behavior-change calculations. In the second term, $p_{s}$ is the change in the probability of two-vehicle crashes when drivers shift from light truck to cars and $d$ is the initial damage level or the probability of fatalities when cars are involved in two-vehicle crashes with light trucks. The result is multiplied by 1 million. 
TABLE 6

External and Internal EfFects of Replacing 1 Million Light Trucks with Cars: Serious-InJury Crashes

\begin{tabular}{|c|c|c|}
\hline & No Behavior Change & Behavior Change \\
\hline \multicolumn{3}{|l|}{ External effects: } \\
\hline $\begin{array}{l}\text { Decrease in number of two-vehicle crashes per year } \\
\text { involving serious injuries of car occupants }\end{array}$ & -215 & -563 \\
\hline Decrease in number of crashes per year involving & -17 & -7 \\
\hline $\begin{array}{l}\text { Decrease in number of crashes per year involving } \\
\text { serious injuries of motorcyclists }\end{array}$ & -14 & -13 \\
\hline Total external effects & -246 & -583 \\
\hline \multicolumn{3}{|l|}{ Internal effects: } \\
\hline $\begin{array}{l}\text { Decrease in number of crashes per year involving } \\
\text { serious injuries of light-truck occupants in } \\
\text { single-vehicle crashes }\end{array}$ & -34 & -189 \\
\hline $\begin{array}{l}\text { Increase in number of two-vehicle crashes per year } \\
\text { involving serious injuries of light-truck }\end{array}$ & & \\
\hline occupants & +362 & +161 \\
\hline Total internal effects & $\overline{+328}$ & -28 \\
\hline External plus internal effects & +82 & -611 \\
\hline Ratio of external effects to internal effects & .75 & Infinite \\
\hline
\end{tabular}

NoTE. - The calculations with no behavior change assume that when 1 million light-truck drivers shift to cars, the number of crashes of each type in which they are involved per year remains constant. The calculations with behavior change assume that when one million light-truck drivers shift to cars, the number of crashes of each type in which they are involved per year changes to the number in which car drivers are involved.

change are beneficial in the behavior-change case, the ratio of external costs to internal benefits is infinite.

To value the benefit of the policy change, I use the fact that each fatal crash involves an average of 1.15 deaths and take the average value of a life to be $\$ 7$ million. ${ }^{28}$ This means that the value of the policy change is $30 \times$ $1.15 \times(\$ 7$ million $)=\$ 242$ million per year in the no-behavior-change case and $81 \times 1.15 \times(\$ 7$ million $)=\$ 652$ million per year in the behaviorchange case. Taking the midpoint of this range, the value of the policy change is $\$ 447$ per year for each vehicle whose type changes from light truck to car.

Now turn to the results in Table 6 for serious-injury crashes. In the nobehavior-change case, the policy change prevents 246 crashes that involve serious injuries of car occupants, pedestrians, bicyclists, and motorcyclists, but it causes 328 additional serious-injury crashes of erstwhile light-truck occupants. Thus, the overall result of the policy change is an increase of 82 serious-injury crashes, and the ratio of external benefits to internal costs is

${ }^{28}$ W. Kip Viscusi \& Joseph E. Aldy, The Value of a Statistical Life: A Critical Review of Market Estimates throughout the World, 27 J. Risk \& Uncertainty 5 (2003). 
only .75 . But in the behavior-change case, the policy change causes 611 fewer serious-injury crashes to occur per year.

How do the benefits of reducing the number of light trucks compare with the benefits of other policy changes that involve driving? Crandall and Graham $^{29}$ estimated that the CAFE standards of the 1970s caused about 300 additional deaths in traffic crashes per year. In comparison, the policy change analyzed here would save between 34 and 93 lives each year, even though it involves substituting only 1 million cars for light trucks. Steven Levitt and Jack Porter ${ }^{30}$ found that seat belts save 11,000 lives per year at a total yearly cost of $\$ 513$ million and that air bags save 2,250 lives per year at a total yearly cost of $\$ 4$ billion. If we value each life saved at $\$ 7$ million, subtract the cost of seat belts and air bags from their benefit, and convert the result to a per-vehicle basis, then the net value of seat belts per vehicle per year is $\$ 413$ and the net value of air bags per vehicle per year is $\$ 64$. The seat belt figure is similar in magnitude to the value of replacing light trucks with cars, which we calculated to be $\$ 447$ per vehicle per year at the midpoint of our upper- and lower-bound estimates. ${ }^{31}$

Overall, the policy change analyzed here generates enormous gains and, because cars are cheaper than light trucks, its costs are negative.

\section{The Failure of Liability Rules, Insurance, AND TRAFFic Rules}

This paper shows that drivers' decisions to drive light trucks rather than cars have extremely large negative external effects and may also have negative internal effects. This section considers whether any of the existing legal institutions-including tort liability, traffic rules, and requirements that vehicle owners purchase liability insurance-internalize these negative effects.

Consider tort liability rules first. Tort liability makes injurers liable for victims' damage under certain circumstances and therefore gives drivers an incentive to use additional care in order to reduce the probability and severity of crashes. In theory, liability for damage should fall more heavily on owners of light trucks than cars, and this should both discourage drivers from purchasing light trucks and encourage them to use additional care if they do purchase these vehicles. But in practice, tort liability has only weak incentive effects. One problem is that liability for damage in the traffic context is generally based on negligence, so drivers are liable only if their care level

\footnotetext{
${ }^{29}$ Supra note 3.

${ }^{30}$ Supra note 17.

${ }^{31}$ Note that the figures for the net value per vehicle of seat belts and air bags are for all vehicles, while the figure for the value of substituting cars for light trucks is a marginal value. If additional cars were substituted for light trucks, then the marginal value would eventually fall as the vehicle fleet became mostly cars. In these calculations, the stock of vehicles in 1997 is assumed to be 185 million, the figure used to construct the crash probabilities in Table 4.
} 
falls below the negligence standard. An optimal negligence standard would require that light-truck drivers take more care than car drivers, since the cost of care is the same for both types of vehicles but light trucks cause greater damage. A related problem is that negligence rules encourage a higher than optimal level of driving activity because drivers escape liability for damage in crashes as long as their care level in driving exceeds the negligence standard. Drivers therefore have an incentive to shift from cars to light trucks because they do not bear the cost of the additional crashes they cause, as long as their driving meets the negligence standard.

The first problem could be solved and the second could be mitigated by raising the negligence standard for light-truck drivers above that for car drivers. For example, lower speed limits could be set for light trucks than for cars, similar to the lower speed limits that are sometimes posted for heavy trucks on freeways. But the tort system in fact applies the same standard of care to drivers of light trucks as drivers of cars.

Another problem with the tort liability system is that many states in the Unites States use no-fault systems, rather than negligence rules, to determine liability in motor vehicle crashes. ${ }^{32}$ In states with no-fault rules, the liability system does not penalize drivers of large and/or heavy vehicles at all for causing higher damage. In fact, drivers of cars are at a disadvantage under no-fault systems, since they suffer more damage in crashes and bear these costs themselves.

Now consider traffic rules, which impose monetary fines, required attendance at traffic school, license suspension, or other penalties on drivers who violate traffic rules. Traffic rules suffer from the same shortcoming as liability rules since the same standard of driving behavior and the same penalties are imposed on drivers of both light trucks and cars. They therefore do not discourage drivers from shifting to light trucks.

Finally, consider liability insurance. Most states require vehicle owners to purchase liability insurance, so that the insurer rather than the driver pays the compensation for damage to victims in crashes when the insured driver is liable. Because many drivers are judgment proof, requiring that drivers purchase liability insurance increases the probability that crash victims will actually be able to collect when they are legally entitled to do so. Also, insured drivers have an incentive to take care in driving, although their insurance companies pay damages, because insurance companies charge higher premiums when their expected liability is higher. These factors suggest that owners of light trucks should pay higher liability insurance premiums than owners of cars, both because they are involved in more crashes and because their vehicles do more damage when crashes occur. But again the

\footnotetext{
${ }^{32}$ As of 1995, 15 states in the United States used some version of no-fault rules for traffic crashes. See Liao \& White, supra note 10, for an analysis of no-fault liability rules in the motor vehicle accident context.
} 
reality is different. Because the negligence and no-fault liability systems often allow drivers to escape liability for damage they cause, owners of light trucks do not necessarily pay higher insurance premiums. Another factor that affects insurance rates is that most states require drivers to purchase only a small amount of liability coverage. Five states do not require drivers to purchase liability insurance at all, one state requires drivers to purchase only $\$ 10,000$ of coverage, and the most common minimum coverage requirement is only $\$ 25,000$. $^{33}$ Since the damage in fatal and serious-injury crashes is far higher, this means that drivers rarely pay for all of the damage their vehicles cause in high-damage crashes. Limited coverage requirements reduce insurance companies' incentive to set higher premiums for larger vehicles because the greater damage that these vehicles cause often exceeds the coverage limit. Another problem is that up to 30 percent of drivers in some states are uninsured. When drivers purchase liability insurance, they typically buy additional coverage for their own damage if they are involved in a crash with an uninsured driver. The cost of uninsured-motorists coverage is higher for drivers of cars than for drivers of light trucks, and this factor tends to raise the relative cost of liability insurance for cars. ${ }^{34}$

These considerations suggest that the negative external effects of large vehicles are not internalized by existing liability rules, traffic rules, or liability insurance. Would any of the reforms that have been proposed recently be effective in internalizing the negative external effects of heavy vehicles? One recently proposed reform, called "pay at the pump," involves bundling liability insurance with gasoline purchases so that all drivers would pay a fixed amount per gallon of gasoline for liability insurance..$^{35}$ The pay-at-the-pump proposal has the advantage of forcing all drivers to purchase liability insurance, and it also charges owners of SUVs and light trucks more for liability insurance per mile of driving than owners of cars since the former get lower gas mileage. The results presented here suggest that the proposal would be

\footnotetext{
${ }^{33}$ The states that do not require owners of vehicles to purchase liability insurance are New Hampshire, Tennessee, South Carolina, Virginia, and Wisconsin. The dollar figures are the required amount of insurance coverage for bodily injury to a single person injured in a crash (higher limits apply if there are multiple victims in a single crash). These figures are taken from Insure.com, Minimum Levels of Required Auto Insurance (March 19, 2002) (available at http://www.insure.com/auto/minimum.html).

${ }^{34}$ Insurance companies follow widely differing practices concerning pricing of liability insurance by type of vehicle. State Farm and GE Auto Insurance charge owners of pickups, SUVs, and large vans less for liability coverage, but Allstate and the Progressive Insurance Group charge owners of these vehicles more. See Joseph B. Treaster, Leading Auto Insurer to Cut Rates for Drivers of the Biggest Vehicles, New York Times, November 28, 2000, at A1; Joseph B. Treaster \& Keith Bradsher, 2 Insurers Raising Liability Coverage on Bigger Vehicles, New York Times, December 2, 2000, at A1; and Car Insurance for Less, Consumer Rep., October 2002, at 19. Bradsher, supra note 2, ch. 10, argues that insurance companies are loath to raise rates on SUV owners because they are more affluent and politically well connected than owners of cars.

${ }^{35}$ See Edlin, supra note 10, for discussion.
} 
beneficial because it would align the cost of insurance more closely with external safety effects. Another recently proposed reform involves imposing strict liability on manufactures of SUVs and pickup trucks-but not carsfor the external harm they cause in crashes. ${ }^{36}$ Other reforms that would improve incentives include raising minimum required levels of liability coverage and replacing no-fault with fault-based liability systems.

Other policies that could be used to discourage people from buying light trucks and SUVs include special excise taxes on the purchase of these vehicles, higher registration fees, and tighter gas mileage standards for these vehicles, freeway tolls based on vehicle size, and higher gasoline taxes generally. All of these policies are in use in Europe, where fewer light trucks are seen.

\section{CONCLUSION}

Traffic deaths in the United States totaled 42,815 in 2002, the highest figure since 1990. Although widespread use of seat belts, campaigns against drunk driving, and adoption of safety equipment such as air bags and antilock brakes caused traffic deaths to fall in the 1970s and 1980s, the number of traffic deaths remained constant during the 1990s and has been rising since 1998. This is at least in part due to the increasing heterogeneity of the U.S. vehicle fleet. As of 2001, there were 77 million light trucks on the road compared with 134 million cars, so a large fraction of crashes involved light trucks that hit smaller vehicles, pedestrians, bicyclists, or motorcyclists. The results of this study show that light trucks are extremely deadly. For each 1 million light trucks that replace cars, between 34 and 93 additional car occupants, pedestrians, bicyclists, or motorcyclists are killed each year in traffic crashes, depending on whether driving behavior is assumed to remain constant or change. The value of the lost lives alone is between $\$ 242$ and $\$ 652$ per year for each light truck that replaces a car. One reason that drivers purchase light trucks is that they think they and their families will be safer in crashes. But for each crash involving deaths of their own occupants that light trucks prevent, they cause at least four additional fatal crashes involving occupants of cars, pedestrians, bicyclists, or motorcyclists.

\section{BIBLIOGRAPHY}

Bradsher, Keith. High and Mighty: SUVs-The World's Most Dangerous Vehicles and How They Got That Way. New York: Public Affairs, 2002.

"Car Insurance for Less." Consumer Reports, October 2002, pp. 19-24.

Coate, Douglas, and VanderHoff, James. "The Truth about Light Trucks." Regulation, Spring 2001, pp. 22-27.

${ }^{36}$ See Howard Latin \& Bobby Kasolas, Bad Designs, Lethal Products: The Duty to Protect Other Motorists against SUV Collision Risks, 82 B.U. L. Rev. 1161 (2002), for discussion. 
Crandall, Robert W., and Graham, John D. "The Effect of Fuel Economy Standards on Automobile Safety." Journal of Law and Economics 32 (1989): 97-118.

Edlin, Aaron S. "Per-Mile Premiums for Auto Insurance." Working Paper No. 6934. Cambridge, Mass.: National Bureau of Economic Research, 1999.

Evans, Leonard. "Accident Involvement Rate and Car Size." Working paper. Warren, Mich.: General Motors Research Laboratories, 1983.

Evans, Leonard. "Car Size and Safety: Results from Analyzing U.S. Accident Data." Working paper. Warren, Mich.: General Motors Research Laboratories, 1985.

Gayer, Ted. "Motor Vehicle Regulations and the Fatality Risks of SportUtility Vehicles, Vans and Pickups." Working paper. Washington, D.C.: Georgetown University, 2002.

Insurance Institute for Highway Safety. Crash Compatibility: How Vehicle Type, Weight Affect Outcomes. Status report. Arlington, Va.: Insurance Institute for Highway Safety, February 14, 1998.

Joksch, Hand; Massie, Dawn; and Pickier, Robert. "Vehicle Aggressivity: Fleet Characterization Using Traffic Collision Data." Working Paper No. HS-808 679. Washington, D.C.: Department of Transportation, 1998.

Keeler, Theodore E. "Highway Safety, Economic Behavior, and Driving Enforcement." American Economic Review 40 (1994): 684-93.

Latin, Howard, and Kasolas, Bobby. "Bad Designs, Lethal Products: The Duty to Protect Other Motorists against SUV Collision Risks." Boston University Law Review 82 (2002): 1161-1229.

Levitt, Steven D., and Porter Jack. "Sample Selection in the Estimation of Air Bag and Seat Belt Effectiveness." Review of Economics and Statistics 83 (2001): 603-15.

Liao, Yu-ping, and White, Michelle J. "No-Fault for Motor Vehicles: An Economic Analysis." American Law and Economic Review 4 (2002): 258-94.

Meyer, John R., and Gomez-Ibanez, Jose A. Autos, Transit and Cities. Cambridge, Mass.: Harvard University Press, 1981.

National Highway Traffic Safety Administration. "A Collection of Recent Analyses of Vehicle Weight and Safety." Working Paper No. HS-807 677. Washington, D.C.: Department of Transportation, May 1991.

National Highway Traffic Safety Administration. "The Effect of Decrease in Vehicle Weight on Injury Crash Weights." Working Paper No. HS-808 575. Washington, D.C.: Department of Transportation, January 1997.

Peltzman, Sam. "The Effects of Automobile Safety Regulation." Journal of Political Economy 83 (1975): 677-725.

Rist, Curtis. "Roll Over, Newton: The Design of Sport Utility Vehicles Is Enough to Make the Father of Physics Turn in His Grave." Discover, April 2001, pp. 44-49. 
Shavell, Steven. Economic Analysis of Accident Law. Cambridge, Mass.: Harvard University Press, 1987.

Treaster, Joseph B. "Leading Auto Insurer to Cut Rates for Drivers of the Biggest Vehicles." New York Times, November 28, 2000.

Treaster, Joseph B., and Bradsher, Keith. "2 Insurers Raising Liability Coverage on Bigger Vehicles." New York Times, December 2, 2000.

U.S. Census Bureau. Statistical Abstract of the United States. Washington, D.C.: U.S. Census Bureau, various years.

Viscusi, W. Kip, and Aldy, Joseph E. "The Value of a Statistical Life: A Critical Review of Market Estimates throughout the World." Journal of Risk and Uncertainty 20 (2003): 5-76.

Wenzel, Tom, and Ross, Marc. "Are SUVs Really Safer Than Cars?" Working paper. Berkeley: Environmental Energy Technologies Division, Lawrence Berkeley National Laboratory, 2002.

White, Michelle J. "An Empirical Test of the Comparative and Contributory Negligence Rules in Accident Law." RAND Journal of Economics 20 (1989): 308-30. 